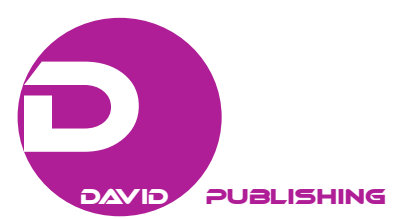

\title{
The Route of Informationization to Promote Agricultural Modernization of Yunnan Province of China*
}

\author{
Li Wenfeng, Zhao Yao \\ Yunnan Agricultural University, Kunming, China
}

\begin{abstract}
Global economic integration and informationization brought opportunities and challenges for agricultural modernization. It is important for the agriculture, the society, the environment, and the sustainable development to correctly understand the connotation and direction of agricultural modernization under the new situation, to efficiently take advantages of information technology and to put forward scientific routes of informationization to promote agricultural modernization. This paper, based on analyzing the agricultural modernization and the current situation of informationization in Yunnan, China, and the challenges and difficulties under the new situation, points out that four ways of realizing informationization to promote agricultural modernization are to transform the market pattern and marketing mode of agricultural product, to support popularizing modern technology in agricultural produce and management, to build resource saving and environment friendly agriculture, and to support the rural reform and social service modernization. This paper indicated that agricultural informationization and modernization need to cooperatively develop. To realize agricultural informationization, four suggestions have been put forward: Sustainable development mode should be adhered to; information service systems should be established by taking actual demands as driving power; information resources should be integrated from multi-source led by government; and a pilot effect of the informationization characterized with agricultural industry and industrial chain should be highlighted.
\end{abstract}

Keywords: Yunnan China, informationization, agricultural modernization, routes

\section{Introduction}

Under the background of economic globalization and informationization, Chinese agriculture enters a new stage of development. Its agricultural modernization shows obvious stage characteristics. Since 1954, when agricultural modernization was put forward in the first China National People's Congress, its concept and connotation were enriched constantly. Agricultural modernization becomes a systematic concept closely associated with era, region. Agricultural modernization experienced four stages in China (Mao \& Kong, 2012). In the 1950's and 1960's, it put emphasis on the application of industrial technology. Scholars generally equated agricultural modernization to agricultural mechanization. In the 1970's and1980's, with the reform in

\footnotetext{
* Project Supported: Philosophy and social science base subject of Yunnan province (JD2015ZD08); Yunnan Agricultural University New Rural Development subject (A2006081).

Li Wenfeng, Ph.D., associate professor, Institute of New Rural Development, Yunnan Agricultural University, Kunming, China. Zhao Yao, master, College of Basic Science and Information Engineering, Yunnan Agricultural University, Kunming, China. Correspondence concerning this article should be addressed to Li Wenfeng, Institute of New Rural Development, Yunnan Agricultural University, Kunming, 650201, China.
} 
the teconomic system, the agricultural modernization was extended to the field of business management and was understood as arming agriculture with modern science and industrial technology but managing agriculture with advanced economic management methods. In the 1990's, market economic system brought marketization and industrialization into the contents of agricultural modernization, together with the modernization of resources allocation and economy structure. In this century, with China joining WTO, the impact of economic globalization and information technology on Chinese agriculture rapidly deepens. The internationalization of market, intellectualization of agricultural management, safety of agricultural products, and protection to the ecological environment have become the important contents of agricultural modernization. In the process of agricultural modernization of China, machinery technology, biological technology, market economic system, management philosophy, and engineering technology had provided strong power successively.

To accelerate the agricultural modernization, Chinese government has been keeping on the policy guidance and support, such as the household contract responsibility system in the 1980's as well as the agricultural products market system and social service system in the 1990's. In this century, the government has issued polices one after another on urban-rural integration, training new farmers, establishing agricultural technology serving system, developing agricultural industrialization, land transferring, and so on. Up to 2015, the first document annual from central government has focused China agriculture for 12 consecutive years. Agriculture is developing rapidly.

Applying information technology in agriculture has got wide attention from Chinese government, academics, and the whole society. In recent years, China has increased investment in the construction of information infrastructure, service system and software platform, the development of software system and new equipments, the integration and demonstration of information technology, and so on, which has produced great influences. In 2011, China's "Twelfth Five Year Plan" proposed to "synchronously improve the industrialization, urbanization, and agricultural modernization". The government report of 2012 also put forward the stategy of "synchronous development in industrialization, informationization, urbanization, and agricultural modernization" in the 18th National Congress $(\mathrm{Hu}, 2012)$. The informatization plays a more and more important role in the national economic and social development. Many domestic scholars have discussed the relationship between informatization and agricultural modernization. It has reached a consensus that information technology is an important technical mean. Some studies regard that the informatization has already integrated into the modern agricultural system as a key element of new productivity and hence become an important content and a carrier for the modern agricultural system (Cui \& Feng, 2013). However, present informatization does not integrate enough with the agricultural modernazation, so that it could not provide sufficient impetus to the latter.

\section{Investigation and Analysis}

Located in the southwest frontier of China, Yunnan is adjacent to Burma, Laos, and Vietnam. Twenty-six ethnic people are living here together, with their various ethical culture and customs. The tropic of cancer gets across the land of Yunnan and results in different climate zones from tropic zone to temperate zone. The diversity of its climates, landforms, and biological resources is very prominent. Yunnan's rural population is high up to $36,203,000$, accounting for $80.2 \%$ of the total population. The gross agricultural production accounts for $26 \%$ of the total value. The economic development level in the rural areas and the whole agricultural production level are both not satisfied. Presently, there are still 6,610,000 impoverished people in rural areas, accounting for $23.7 \%$ of the total rural population in Yunnan province. 


\section{Analysis on the Status of Yunnan's Agricultural Modernization}

Yunnan's agricultural modernization possesses distinct characteristics and difficulties. Its agricultural production level lags behind Chines national average level, which is mainly related with its characteristics of environment, location, economy, and agriculture itself. Firstly, from the aspect of environment, plateau mountain area accounts for $94 \%$ of the province. Its topography is complex. The vertical climate change is very significant. It is not uncommon to see various small climates within a county's region, which even belongs to different climate zones. It brought many difficulties in agricultural standardization and large-scale farming. Secondly, located in the upstream areas of six rivers flowing through China and Southeast Asia, Yunnan has set up many nature protection areas with huge size. To protect the ecology, ecology biodiversity, and restore the environment is a necessary work demanded by China and the world, which is not so coordinated with the strategies of the high-invest and industralization of agriculture, so that the modern agricultural development is restricted. Thirdly, the farmers' scientific and cultural qualities are relatively poor. People with education background above senior middle-school accounted for $14.2 \%$ of the population over six-year-old and $41.6 \%$ above junior high school. Fourthly, the contribution rate of science and technology is not high for agriculture. The total power of using agricultural machinery to cultivate land was $4.2 \mathrm{kw} / \mathrm{ha}$ in 2013, which was far less than the national average level of $5.7 \mathrm{kw} / \mathrm{ha}$ (Agriculture Department of Yunnan Province, 2014). According to the above, the modernization of agriculture should take the specialties of agricultural and environment as well as the protection of ecological environment into consideration. It is also an important content to improve the quality of farmer in science and technology.

\section{Analysis on the Status of Yunnan's Agricultural Informatization}

According to "the global information technology report in 2012" from the world economic forum, if using the Networked Readiness Index, to show the national informatization levels of all nations, the mainland of China only ranks the 51. Yunnan's informatization even lags behind China's average level. The rural informatization in Yunnan province developed rapidly after 2000. Broadband network covered $44 \%$ administrative villages in the province in 2009 . The $3 \mathrm{G}$ network covered all towns and most administrative villages.

The rural informatization in Yunnan province lags far behind the developed areas. The service for agricultural modernization by informatization is obviously insufficient and shows many problems. Firstly, because of limit sci-tech knowledge, the farmers do not put emphasis on the agricultural information and can not use information technology well. Secondly, present agricultural informatization mainly serves in the technology support and production management, lack of pre-planning before production, and logistic service after production. Thirdly, the agricultural information service system is incomplete. Although 392 rural information service stations have been established, the promotion of information service is difficult to carry out because of the shortage of information workers and utility of software, so that it is hard to produce actual effects. Fourthly, the agricultural information resources are too disperse and intermingled by the good and bad. The user can not distinguish the useful ones easily. Fifthly, the agricultural informatization is still dominated by government, with little social joined. At last, the support of informatization to the industry is far from enough. Only about $10 \%$ national agricultural industrialization leading enterprises of Yunnan can realize digital distribution and online trade online through their websites. Around $60 \%$ provincial agricultural leading enterprises established websites, but most of these websites are only used to introduce the enterprises and their products. 


\section{Discussion and Conclusions}

\section{The Route of Informatization to Promote Agricultural Modernization}

(1) To promote the transformation in market structure and managerial mode of agriculture.

The market is the best internal impetus for agricultural modernization. Informatization possesses great potential in changing the market structure and the mode of agricultural operation. Through electronic commerce, information tracing, and data mining technology, many new sales models can be developed, such as the network sale mode, direct sales mode contacting producers with consumers, and intelligent sales mode letting the products choose consumers. Agricultural informatization should also promote the internationalization in the production and management of agriculture.

(2) To promote the modernization of the agricultural production and management technologies.

The main form of applying information technology in agriculture is to spread modern technology of production and management through the information technologies. In the future, the service of information platform should be strengthened. Efforts should be done to improve the production automation, standardization, and industrialization. The integration of information resources and information technologies also should be enhanced, which includes the Internet of things, cloud computing, mobile Internet, and 3S. The precision agriculture and intelligent agricultural should get more focus.

(3) To promote resource-saving and environment-friendly agriculture.

Resource conservation and environmental protection have early become important connotations of modern agriculture. Agricultural modernization should pay more attention to precision agriculture and ecological agriculture. Based on the environmental conditions and production requirements, information technology can be used in scientific planning, accurate management of production, improving the utilization rate of resources, and promoting the coordinated development of agriculture and environment protection.

(4) To promote the modernization of rural affairs management and social service.

Rural informatization is also important, by which farmers can be trained to enhance the scientific and cultural quality of farmers. Farmers also can get more public service. Rural e-government is another important job, to improve rural affairs management efficiency, promote the openness of government information, and improve the level of democracy and legalization.

\section{Suggestion of Agricultural Informatization}

Agricultural modernization and informatization of agriculture should be done cooperatively, not respectively. Anyone should guide one another. According to the current situation and demands, this paper puts forward the suggestions of agriculture informatization. The first is to innovate in the mechanism to keep agricultural informatization sustainable. By the way of market mechanism, the more social force should be encouraged to take part in agricultural information. Service should be distinguished from "public service" or "marketing services". The second is to set an information service system driven by actual demands. Many problems have emerged in the process of agricultural informatization, such as too much content, too high target, and excessive informalism. The key content and the preferred direction should be determined firstly by actual demands. Then it is needed to build a systemic system for information service. The system includes hardware, software, facilities, personnel, information resources, etc. The third is to integrate information resources led by the government. Institutions involved in agriculture are so much, and each of them accumulated rich information, facilities, human resources, and other resources. These resources were scattered and used not 
enough. Some were collected many times. The government should organize related institutions to integrate information resources and share it to public with a unified platform. The fourth is to highlight the informatization in special industries and industry chains. Higher investment and later effect are important obstacles in agricultural informatization, so special industries with higher output should be supported prior through agricultural enterprises. This way will relieve the economic pressure. Informatization for agricultural industrial chain also should be emphasized. Beside production, the management, logistics, processing, sales, and other links need to be serviced by information, so that the maximum benefits from informatization would centralize as soon as possible. It will help to expand the demonstration effect.

\section{References}

Agriculture Department of Yunnan Province. (2014). Yunnan agriculture yearbook 2013. Kunming, KM: Yunnan People's Press.

Cui, K., \& Feng, X. (2013). Exploration on the historical course and development trend of harmonized promoting of industrialization, informatization, urbanization and agricultural modernization since the founding of PRC. Guangdong Agricultural Sciences, 40(16), 201-206.

Hu, J. T. (2012). Firmly march on the path of socialism with Chinese characteristics and strive to complete the building of a moderately prosperous society in all respects (Report to the Eighteenth National Congress of the Communist Party of China). Socialist Forum, 2012(12), 4-16.

Mao, Z., \& Kong, X. Z. (2012). The general status and the trend in future of agriculture modernization in China. Reform, 2014(10), 9-21. 